This is the author's final, peer-reviewed manuscript as accepted for publication. The publisher-formatted version may be available through the publisher's web site or your institution's library.

\title{
Measurement of sticky point temperature of coffee powder with a rheometer
}

Rumela Bhadra, K. Muthukumarappan, Kurt A. Rosentrater

\section{How to cite this manuscript}

If you make reference to this version of the manuscript, use the following information:

Bhadra, R., Muthukumarappan, K., \& Rosentrater, K. A. (2013). Measurement of sticky point temperature of coffee powder with a rheometer. Retrieved from http://krex.ksu.edu

\section{Published Version Information}

Citation: Bhadra, R., Rosentrater, K. A., \& Muthukumarappan, K. (2013). Measurement of sticky point temperature of coffee powder with a rheometer. International Journal of Food Properties, 16(5), 1071-1079.

Copyright: Copyright $\odot$ Taylor \& Francis Group, LLC

Digital Object Identifier (DOI): doi:10.1080/10942912.2011.576359

Publisher's Link:

http://www.tandfonline.com/doi/full/10.1080/10942912.2011.576359\#.U17F_4FdXL8

This item was retrieved from the K-State Research Exchange (K-REx), the institutional repository of Kansas State University. K-REx is available at http://krex.ksu.edu 


\title{
Measurement of sticky point temperature of coffee powder with a rheometer
}

\author{
Running Head: Ts measurement with a rheometer
}

Author(s)

Rumela Bhadra, Graduate Research Assistant, Department of Agricultural and Biosystems

Engineering, South Dakota State University, South Dakota. Email: rumelabhadra31@yahoo.com Address: 1400 North Campus Drive, South Dakota State University, Brookings, SD-57007.

\section{K. Muthukumarappan, PhD, Professor, Department of Agricultural and Biosystems}

Engineering, South Dakota State University, South Dakota. Email: muthukum@ sdstate.edu Address: 1400 North Campus Drive, South Dakota State University, Brookings, SD-57007.

Kurt A. Rosentrater, PhD, Lead Scientist and Bioprocess Engineer, United States Department of Agriculture-Agricultural Research Service. Email: kurt.rosentrater@ars.usda.gov Address: 2923 Medary Avenue, North Central Agricultural Research Laboratory, USDA-ARS, Brookings, SD-57006.

Corresponding author: Kurt A. Rosentrater, PhD, Lead Scientist \& Bioprocess Engineer, Address: 2923 Medary Avenue, North Central Agricultural Research Laboratory, USDA-ARS, Brookings, SD-57006. Email: kurt.rosentrater@ars.usda.gov

Phone: (605)-693-5248; Fax: (605) 693-5240

Bhadra et al. 


\section{ABSTRACT}

28 Sticky point temperature (Ts) is a parameter that quantifies stickiness of food and biological 29 powders. It is traditionally measured using glass instruments. In this study we developed a new 30 methodology to measure sticky point temperature using a rheometer, and we successfully used it 31 to determined Ts for coffee powder samples. The behavior of coffee Ts as a function of moisture 32 content $(\%, \mathrm{db}$ (i.e., dry basis)) was observed to be non-linear, but after $16 \%$ (db) moisture 33 content, there were no changes in Ts with further increases in moisture content. An exponential 34 prediction model for $\mathrm{Ts}=\mathrm{f}$ (moisture content) was achieved with an $\mathrm{R}^{2}$ value greater than 0.93 ; $\mathrm{a}$ 35 power law regression model also fitted well, with an $\mathrm{R}^{2}$ value of 0.97 . Rheometry was shown to 36 be a viable and convenient means to determine Ts for various coffee powders.

Keywords. Caking, coffee, rheometer, sticky point temperature, stickiness

43 A large variety of powders are generated industrially and thus there is a great need for 44 information about their handling, storage, and processing characteristics. Cohesive attraction and 45 frictional resistance developed between particles in a powder when consolidated (due to handling 46 and storage) must be overcome to make the powder flow efficiently, otherwise cohesive arches

47 will prevent the smooth discharge of the materials. For proper flowability and discharge of 48 powder materials, knowledge of cohesive attractive forces is necessary to design the minimum 
49 size of hopper openings. Thus, overcoming cohesive forces and characterizing cohesion

50 phenomena is very important (1). Food powders and food component mixes make the problem of

51 caking even more difficult due to the complex ingredients present in these systems. Furthermore,

52 during processing, handling, storage, and distribution of food powders to final consumers, there

53 is a possibility for the material to experience variable environmental conditions (i.e.,

54 temperatures), thus there is a high probability of caking and flowability problems.

56 Stickiness is a phenomenon that reflects the propensity of powders to agglomerate and to adhere

57 to contact surfaces (2). Stickiness and caking are commonly encountered problems in food

58 powders and other sugar-rich powders which are amorphous in nature (3).. Powder stickiness

59 and caking are phenomena related to this structural collapse (4). Often structural collapse,

60 stickiness, and caking of powders are strongly influenced by moisture content, and these

61 behaviors are often time dependent (4).

62

63 The mechanisms of particle stickiness and agglomeration are mostly due to intermolecular and

64 electrostatic forces, liquid bridges, solid bridges, and/or mechanical interlocking of particles (5).

65 Food and biological powders often contain amorphous carbohydrates that undergo physical

66 changes such as crystallization, clumping, sticking, and caking during processing and handling

67 (6). Although these changes are not desirable during storage, stickiness of powders can

68 sometimes be an advantage when making agglomerated food products like instant coffee, milk

69 powders and other related applications (3). For example, for instant coffee, milk, and fruit juice

70 powders, agglomeration is often required to enlarge particle size, generally from $50-80 \mu \mathrm{m}$ to

$71250-300 \mu \mathrm{m}$, in order to obtain good 'instant powder' properties such as wetability,

72 dispersibility, and solubility (7).

73

Bhadra et al.

International Journal of Food Properties 
74 In addition to the usual disadvantage of stickiness and agglomeration in storage and handling of

75 powders, they can also negatively impact drying operations $(8,9,10)$. Malto dextrins are widely

76 used in food components to increase viscosity, to reduce crystallization, to improve drying

77 characteristics, to decrease hygroscopicity, and to decrease stickiness of dried food powders (11).

78 The most commonly used method to quantify and characterize stickiness and caking potential of

79 food and biological powders is the glass transition temperature (Tg) (Bhadra et al. (12); Chuy

80 and Labuza (13); Farkas and Farkas (14); Fujio and Lim (15); Ganesan et al. (16); Jaya and Das

81 (17); Roos and Kharel (11))

82

83 Apart from Tg, sticky point temperature (Ts) is also used to measure and quantify the stickiness

84 and caking of powders.. Sticky point temperature measurement was initially developed by Lazar

85 et al. (18), and then it was applied by other researchers for measuring stickiness in various food

86 powders $(3,9)$. As stated in Lazar et al. (18), the sticky point temperature of tomato juice powder

87 was determined empirically by inserting the sample vessel into a water bath, and then the

88 temperature of the bath was slowly raised. The powder was stirred intermittently by rotating a

89 propeller $1 / 4$ turn at a time. The sticky point temperature was defined as the bath temperature at

90 which the force or torque necessary to stir the propeller increased sharply (i.e., a critical point). It

91 was found that sticky point temperature for tomato powder showed an inverse relationship with

92 moisture content. In order to prevent moisture loss from the samples during testing, mercury

93 seals were provided in the glass tube. More detailed descriptions of this arrangement can be

94 found in Wallack and King (3) and Lazar et al. (18).

96 The most widely accepted definition of sticky point temperature is the combination of 97 temperature and moisture content for which the given mass of the powder resists propeller 98 movement and is no longer free-flowing. A representative diagram of sticky point curves and Bhadra et al. International Journal of Food Properties 
99 sticky regions of general food powders is given in Figure 1. In moisture content vs. temperature

100 coordinates, the sticky point (or stickiness) curve provides a sharp boundary between the sticky

101 region below the curve, and the non-sticky region above the curve (2). Figure 1 shows that the

102 granular non-sticky particles (below the lower boundary Ts curve) can be converted to sticky

103 mass with increase in moisture content and increase in temperature. Further increase in moisture

104 content or temperature would ideally convert the sticky material to liquid state, crossing the

105 upper boundary Ts curve. Previous research studies with coffee powder by Wallack and King (3)

106 also revealed a stickiness curve with a change in moisture content. For Wallack and King (3)

107 data, the lower boundary of the Ts curve (the non-sticky discrete particles), and the sticky region

108 were considered as the sticky point curve.

109

110 Since its inception, sticky point temperature has been studied for various powder products, and it

111 has been determined that stirring devices work best (9). In order to avoid tedious manual stirring,

112 Brennan et al. (19) used a motor-driven stirrer. In a study by Hennigs et al. (20), a DC-motor

113 driven stirrer was applied to a sample at $38 \mathrm{rpm}$. To eliminate the several disadvantages of the

114 traditional Ts method, such as excessive evaporation, tedious manual stirring, fragile glass 115 apparatus, as well as using dangerous mercury compounds, the traditional method of Ts 116 measurement should be modified with a more sophisticated approach. Thus, the objectives of 117 this study were: (i) To develop a new method to measure sticky point temperature (Ts) using a 118 semi-automated rheometer. (ii) To validate vis-à-vis the coffee powder sticky point temperature 119 (Ts) data obtained by using the new rheometer method with the previously published research of 120 Wallack and King (3). (iii) To developed a regression model for predicting sticky point 121 temperature (Ts) as a function of moisture content. 
127 Commercial Arabica plantation coffee powder, with an initial moisture content of $6.5 \%(\mathrm{db})$, 128 was procured from market (Walmart Stores, SD). Moisture content analysis was carried out using an AACC standard method (21). Similar results for coffee powder moisture content were

130 found by Ramalakshmi et al. (22) for Arabica variety. The coffee variety that was used by 131 Wallack and King (3) is not reported clearly. Hence, we could not match the coffee variety of the 132 test samples with Wallack and King (3).The coffee powder samples were then prepared for 133 experimentation by drying to about $0 \%$ moisture content (db) (this was achieved by drying the 134 coffee powder for 8 hours at $50^{\circ} \mathrm{C}$ ), and then adding amounts of water to achieve specific 135 moisture contents of $4,6,8,10,12,14,16,20$, and $25 \%(\mathrm{db})$. After moisture adjustment, the 136 137 was performed twice (i.e. $\mathrm{n}=2$ ).

\section{Ts Measurement}

141 The traditional method of sticky point temperature measurement used a glass apparatus and a 142 propeller with pointed, flat wedge tips. Ts measurement using the traditional glass apparatus is 143 shown in studies carried out by Papadakis and Bahu (5) and Wallack and King (3). The powder 144 sample was placed in a glass tube where the propeller was inserted and then mechanically stirred. 145 The glass tube was then placed in a water bath. In order to avoid moisture evaporation, a 146 mercury seal was used. The water bath temperature was then raised about $1{ }^{\circ} \mathrm{C}$ every 3 min (at 
147 temperatures far below the sticky point temperature but for temperature near the actual sticky

148 point temperature the water bath temperature rise was about $1^{\circ} \mathrm{C}$ every $5 \mathrm{~min}$ ). Heating was done

149 slowly so that the powder temperature remained in equilibrium with the bath temperature. The

150 propeller was generally turned manually $1 / 4$ revolution every other second. In order to ensure

151 proper contact between the powder and the propeller, the sample tube was tapped periodically.

152 At some points, as the bath temperature increased the force required to stir the sample drastically

153 increased (i.e., a critical point was reached). The particular temperature (for a given moisture

154 content) at which the force required to stir the sample increased is known as sticky point

155 temperature (Ts). Detailed further discussions of Ts measurement can be obtained from Wallack

156 and King (3) and Papadakis and Bahu (5).

158 Although never done before, to measure Ts in this study, we used a rheometer (Viscoanalyzer, 159 ATS Rheosystems, Bordentown, NJ) with a cup and vane tool arrangement. The vane tool was a 1604 blade stirrer (model 4/13.5, Viscoanalyzer, ATS Rheosystems, Bordentown, NJ) made of 161 stainless steel with a stress coefficient of $4.15 \times 10^{4} \mathrm{~Pa} / \mathrm{N} \cdot \mathrm{m}$, strain coefficient of $0.931 / \mathrm{s} / \mathrm{rad}$, 162 and inertia of $2.05 \mathrm{x} 10^{7} \mathrm{~kg} \cdot \mathrm{mm}$. The vane tool was inserted into the heated sample cup (model 163 CC25, Viscoanalyzer, ATS Rheosystems, Bordentown, NJ). Figure 2 provides a pictorial view of 164 the experimental set up used in this study. Figure 3 illustrates the 4 blade vane attachment, with 165 dimensions of $36.79 \mathrm{~mm}$ (length) $\times 6.78 \mathrm{~mm}$ (width) (the shaft of the propeller was $105.63 \mathrm{~mm}$ 166 in length) as it is being inserted into the cylindrical sample cup (which had an internal diameter 167 of $26.68 \mathrm{~mm}$, external diameter of $32.58 \mathrm{~mm}$, and height of the $65 \mathrm{~mm}$ ). Both the sample cup 168 and the vane attachment were made of stainless steel. The sample cup was filled approximately $16950 \%$ full with the sample material, and then the vane tool was inserted into the cup. 
171 The sample temperature was regulated with a thermostat that increased the cup temperature from

17220 to $80^{\circ} \mathrm{C}$. The shear rate used was $0.251 / \mathrm{s}$, and the increasing temperature rate was $2^{\circ} \mathrm{C}$ rise in

173 every $3 \mathrm{~min}$ (or $0.67{ }^{\circ} \mathrm{C} / \mathrm{min}$ ), with an entire temperature span of $60^{\circ} \mathrm{C}$. This combination of

174 temperature, time, and shear rate was selected after preliminary trials with the coffee powder

175 samples (data are not shown). As the traditional method, the temperature at which the torque

176 showed a dramatic increase in value was identified as the sticky point temperature. Torque is a

177 measurement for twisting forces or tendency for force to rotate an object on axis.

179 Data Analysis

180

181 Statistical regression modeling and analysis using SAS software (SAS Institute, Carry, NC) were

182 performed to obtain the best fit model to predict Ts as a function of moisture content. Graphs 183 were produced using MS Excel (v. 2003) software.

\section{Validation of Ts Data}

187 To examine the validity of rheometry as an appropriate means to quantify sticky point 188 temperature, we compared our results with that of Wallack and King (3), where the traditional 189 glass apparatus was used to measure coffee powder sticky point temperature.

\section{$191 \quad$ RESULTS AND DISCUSSION}

192 The sticky point temperature (Ts) curve for coffee powder samples used in this study is 193 presented in the Figure 4. We had two replications for each moisture contents and can clearly 194 observe that the Ts readings were very close for both the replications. This indicates that our 
rheometer-based Ts measurement procedure was fairly precise. Figure 4 presents the Ts data

196 from Wallack and King (3) superimposed with our data. For Wallack and King, the range of 197 moisture contents for their coffee powder samples was from $4 \%$ (db) to $14 \%$ (db). However, for 198 our coffee powder samples, moisture contents ranged from $4 \%$ (db) to $25 \%$ (db). This was 199 purposely done to understand and evaluate the Ts curve for a higher range of moisture contents. 200 The Ts curve as reported by Wallack and King (3) (Figure 4), showed a fairly linear pattern until $201 \sim 7 \%(\mathrm{db})$ moisture content, and then there was a non-linear decrease in the Ts values as the 202 moisture content increased up to $14 \%(\mathrm{db})$. Almost similar results were observed for our coffee 203 powder samples, as indicated in Figure 4. From Figure 4 we also observe that for moisture 204 contents higher than $\sim 15 \%$ (db) there was little change in the resulting Ts, and as the moisture 205 content increased the curve remained almost unchanged with less decrease in Ts values..

207 From Figure 4 , we clearly note that as the moisture content of the coffee powder increased, the 208 Ts decreased, which indicates that the coffee powder has greater tendency to stick (at the lower 209 temperature regions) and create flow problems. This typical Ts curve confirms that for low 210 moisture contents $(<15 \%(\mathrm{db}))$ if only the temperature is raised high above $40^{\circ} \mathrm{C}$, then the 211 particle-particle cohesion takes place which triggers stickiness in coffee powder. On the other 212 hand, for moisture contents $(>15 \%(\mathrm{db}))$ particle cohesion was observed for temperature 213 between 30 to $40^{\circ} \mathrm{C}$. Ts decreased significantly for lower moisture levels $(<15 \%$, db) because 214 increase in water would facilitate more in liquid mobile bridge formation which is the main 215 cause of particle cohesion, and stickiness at lower temperatures. Thus, it was confirmed that Ts is 216 an inverse function of moisture content. A similar result was observed by Lazar et al. (18) for 217 spray dried tomato powders. Stickiness is a major constraint that limits the spray drying of 218 various sugar-rich foods. High hygroscopicity of amorphous powders increases the solubility of 219 the sugars with temperature, and therefore a lower melting point and glass transition temperature Bhadra et al. International Journal of Food Properties 
region is observed, contributing to stickiness in powders. The presence of sugar molecules in

221 food powders may keep the product in the liquid/syrup state, instead of a complete dried powder

222 form, which may further contribute to powder stickiness (18).

223

224 It has been shown in previous reports that $\mathrm{Ts}$ and $\mathrm{Tg}$ (glass transition temperature) are very 225 closely correlated, and both can be used to assess stickiness of powder materials (8). More

226 details can be found in Ozmen and Langrish (8), Roos and Kharel (23), Adhikari et al. (24), and

227 Werner et al. (25). Figure 4 presents the validation of rheometer-based Ts curve for coffee

228 powder vis-à-vis Wallack and King's data (3). We can clearly see that the data produced by our

229 method showed very close results to those of Wallack and King (3). The rheometer-based Ts

230 measurement used sophisticated computer software and generated the torque values

231 automatically, so the rheometer method resulted in higher precision than the traditional glass

232 apparatus method, where there was no automation involved in the procedure.

234 After examining coffee powder Ts as a function of moisture content, and validating our Ts data

235 with that of Wallack and King (3), we moved one step further, and obtained a single regression

236 model that could predict Ts for all moisture contents. As shown in Table I, all models worked

237 well, but a power law of regression equation was best to predict $\mathrm{Ts}=\mathrm{f}$ (moisture content), with an

$238 \mathrm{R}^{2}$ value of 0.97 and very low standard error of the mean (SEM) value of 2.73. The 239 corresponding plot of this regression model for predicted Ts vs. observed Ts is illustrated in

240 Figure 5. From Table I, we observe that for the polynomial regression equation, the $\mathrm{R}^{2}$ was high 241 (0.99), but this model was not selected as optimal due to the extremely high SEM value. 242 Although not examined in this study, for glass transition temperature (Tg), the Gordon-Taylor 243 model (26) can be used to predict $\mathrm{Tg}=\mathrm{f}($ moisture content $)$. 


\section{CONCLUSIONS}

247 This study establishes a new method for measuring sticky point temperature (Ts) using a 248 rheometer. This method has several obvious advantages over the traditional method. This

249 procedure is more automated, fast, easy to handle, more precise than the traditional process, and 250 does not rely on a glass apparatus or mercury seals. Our research also validates Ts data over 251 varying moisture contents with previously published research on coffee powder. This innovative 252 approach should help the food and powder industries to measure Ts more efficiently.. More 253 validation studies with other food samples should be done to test the effectiveness of this 254 procedure.

\section{ACKNOWLEDGEMENTS}

258 The authors would like to extend their gratitude to South Dakota State University and USDA259 ARS for the financial support for this project. The authors would also like to extend their 260 appreciation to the South Dakota Corn Utilization Council (SDCUC) and Agricultural 261 Experimental Station (AES).

\section{REFERENCES}

264 1. Fitzpatrick, J. J.; Hodnett, M; Twoney, M; Cerqueira, P. S. M.; O’Flynn, J; Roos, Y. H. 265 Glass transition and flowability and caking of powders containing amorphous lactose. $266 \quad$ Powder Technology. 2007, 178(1), 119-128. 
2. Kudra, T. Sticky region in drying - definition and identification. In Report No: CETC Number 2002-057 / 2002-04-05. CANMET, Energy Diversification Research Laboratory, Varennes, PQ, Canada. 2002. Available at: http://canmetenergycanmetenergie.nrcan-ncan.gc.ca/eng/publications.html?2002-057 Accessed on March 10, 2010. carbohydrate and food powders. Biotechnology Progress. 1988, 4(1), 31-34. food technology: a critical appraisal. Journal of Food Science. 2002, 67(7), 2444-2458.

5. Papadakis, S. E.; Bahu, R. E. The sticky issues of drying. Drying Technology. 1992, 10(4), 871-837.

6. Levine, H.; Slade, L. A polymer physico-chemical approach to the study of commercial starch hydrolysis products (SHPs). Carbohydrate Polymers. 1986, 6(2), 213-244.

8. Ozmen, L.; Langrish, T. A. G. Comparison of glass transition temperature and sticky point temperature for skim milk powder. Drying Technology. 2006, 20(6), 1177-1192.

7. Gianfrancesco, A. Controlled powder agglomeration during the spray drying process. In Proceedings of Mini-Conference, Biopowders - Properties, Production and Handling, $29^{\text {th }}$ and $30^{\text {th }}$ June, Gothenburg, Sweden, 2006. pp. 5-7

9. Downton, G. E.; Flores-Luna, J. L.; King C. J. Mechanism of stickiness in hygroscopic, amorphous powders. Industrial Engineering and Chemical Fundamentals. 1982, 21(3), 447-451. Journal of Agricultural Science. 2007, 3(2), 230-236.

11. Roos, Y.; Karel, M. Phase transitions of mixtures of amorphous polysaccharides and sugars. Biotechnology Progress. 1991, 7(1), 49-53.

Bhadra et al. 
12. Bhadra, R.; Kannadhason, S; Muthukumarappan, K.; Rosentrater, K. A. Drying kinetics of DDGS under varying CDS and temperature levels. ASABE International Conference, Reno, NV, 2009. ASABE Paper No: 096614.

13. Chuy, L. E.; Labuza, T. P. Caking and stickiness of dairy-based food powders as related to glass transition. Journal of Food Science. 1994, 59(1), 43-46.

14. Farkas, J.; Mohácsi-Farkas, C. Application of differential scanning calorimetry in food research and food quality assurance. Journal of Thermal Analysis. 1996, 47(6), 17871803.

15. Fujio, Y.; Lim, J. K. Correlation between the glass transition point and color change of heat-treated gluten. Cereal Chemistry. 1989, 66(4), 268-270.

16. Ganesan, V.; Rosentrater, K. A. Characterization of DDGS using differential scanning calorimetry. CSBE/ASABE North Central Intersectional Conference, Fargo, ND, 12-13 October, 2007. ASABE Paper No: RRV-07147.

17. Jaya, S.; Das, H. Glass transition and sticky point temperatures and stability/mobility diagrams of fruit powders. Food and Bioprocess Technology. 2009, 2(1), 89-95. production of tomato powder by spray drying. Food Technology. 1956, 3(1), 129-134. drying of concentrated orange juice, on a laboratory scale. Journal of Food Technology. 1971, 6(2), 295-307.

20. Hennigs, C.; Kockel T. K; Langrish, T. A. G. New measurements of sticky behavior of skim milk. Drying Technology. 2001, 19(3\&4), 471-484.

21. AACC. 44-19. Moisture-air oven method, drying at $135^{\circ} \mathrm{C}$. AACC Approved Methods ( ${ }^{\text {th }}$ ed.). St Paul, MN, 1995. 
22. Ramalakshmi, K.; Kubra, I. R.; Rao, L. J. M. Physiochemical characteristics of green coffee: comparison of graded and defective beans. Journal of Food Science. 2007, 72(5), S333-S337.

23. Roos, Y.; Kharel, M. Differential scanning calorimetry study of phase transitions affecting the quality of dehydrated materials. Biotechnology Progress. 1990, 6(2), 159163.

24. Adhikari, B.; Howes, T; Bhandari, B. R.; Truong, V. Stickiness in foods: a review of mechanisms and test methods. International Journal of Food Properties. 2001, 4(1), 1-33.

25. Werner, S. R. L.; Franshawe, R. L.; Paterson, A. H. J.; Jones, J. R.; Pearce, D. L. Stickiness of corn syrup powders by fluidized bed test. International Journal of Food Engineering. 2006, 2(5), 1-10.

328

26. Gordon, M.; Taylor, J. S. Non crystalline copolymers. Journal of Applied Chemistry. 1952, 2(2), 493-500.

\section{$331 \quad$ Disclaimer}

334 guarantee or warranty by the United States Department of Agriculture and does not imply 335 approval of a product to the exclusion of others that may be suitable. 


\section{Table 1: Regression modeling results for predicted $\mathrm{Ts}=\mathrm{f}($ moisture content $){ }^{\dagger}$}

\begin{tabular}{|c|c|c|c|c|c|c|c|c|}
\hline \multirow[b]{2}{*}{ Model } & \multirow[b]{2}{*}{ Type of model } & \multicolumn{2}{|c|}{ Model Performance } & \multicolumn{5}{|c|}{ Parameters Estimates } \\
\hline & & $\mathbf{R}^{2}$ & SEM & A & b & c & d & e \\
\hline $1 \quad \mathrm{y}=\mathrm{ax}^{(\mathrm{b})}$ & Power law & 0.97 & 2.73 & 248.12 & -0.77 & & & \\
\hline $2 \quad \mathrm{y}=\mathrm{ae}^{(\mathrm{bx})}$ & Exponential & 0.94 & 4.70 & 107.54 & -0.09 & & & \\
\hline $3 \quad y=a x^{4}+b x^{3}+c x^{2}+d x+e$ & Polynomial & 0.99 & 689.60 & -0.03 & 0.90 & -0.92 & 26.47 & 77.88 \\
\hline
\end{tabular}

$\dagger$ Where $\mathrm{y}$ is predicted Ts; $\mathrm{x}$ is moisture content $(\%, \mathrm{db})$; SEM is standard error of the mean; $\mathrm{a}, \mathrm{b}, \mathrm{c}, \mathrm{d}$, and e are the estimated model parameters; $\alpha=0.05$. 


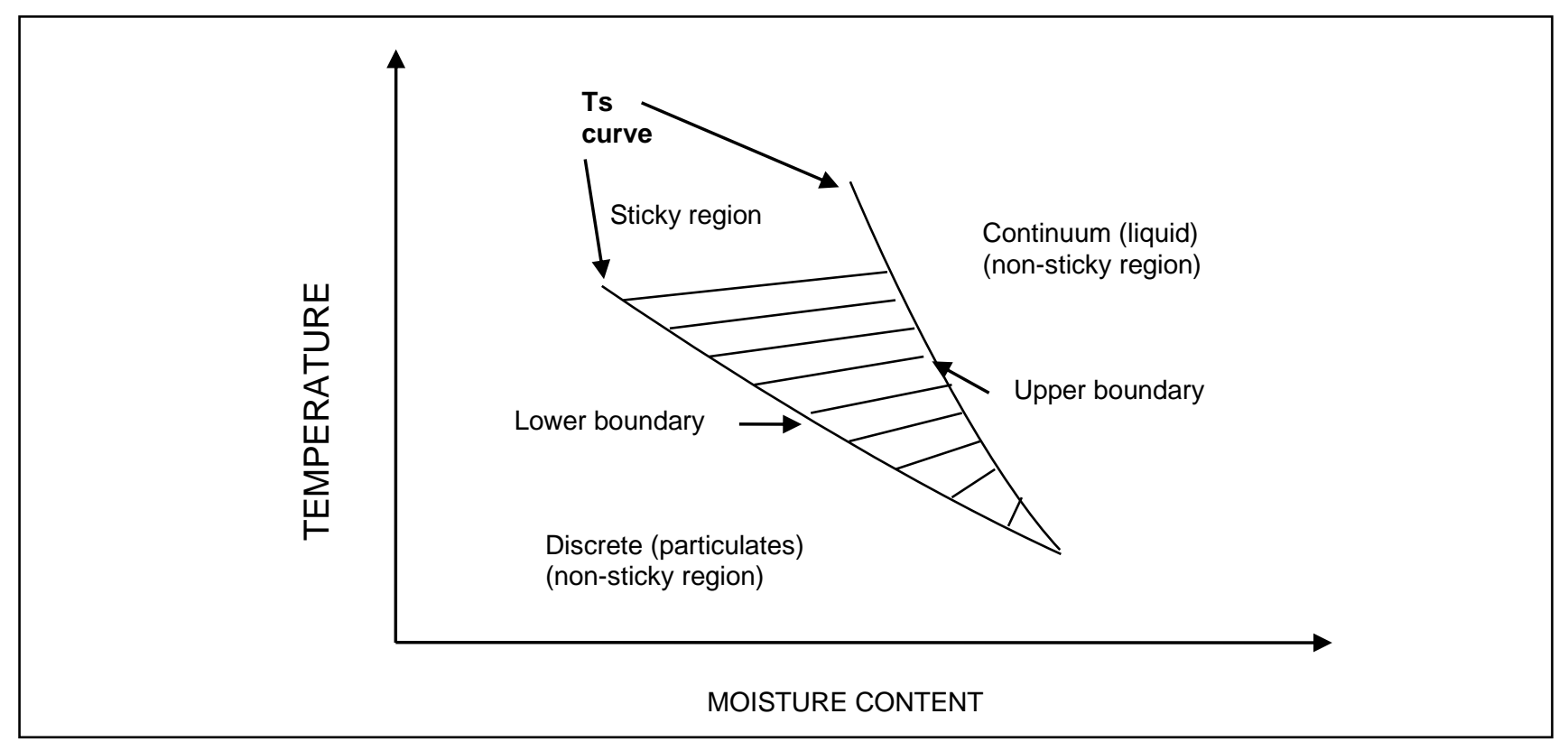

Figure 1 


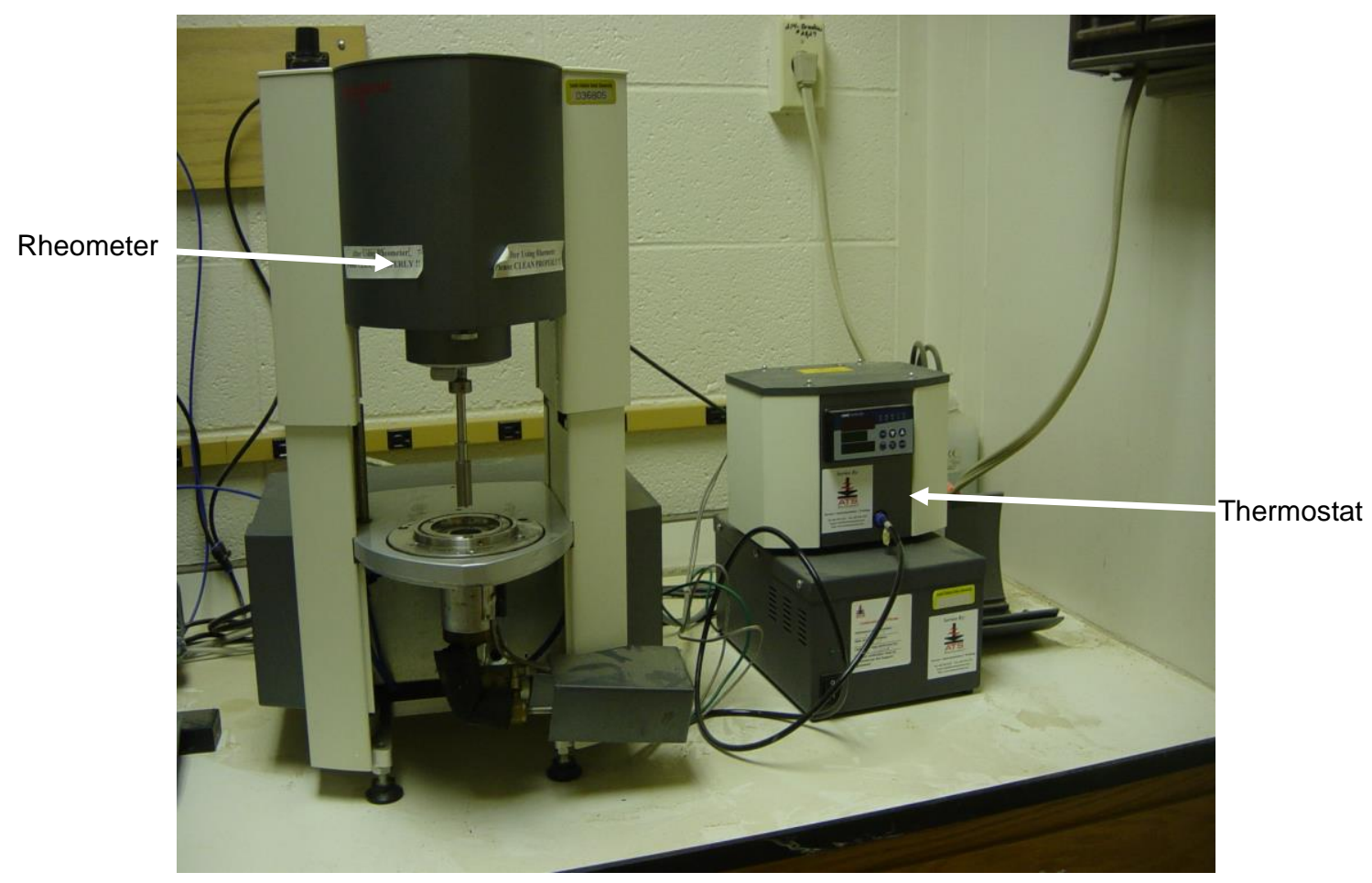

Figure 2 


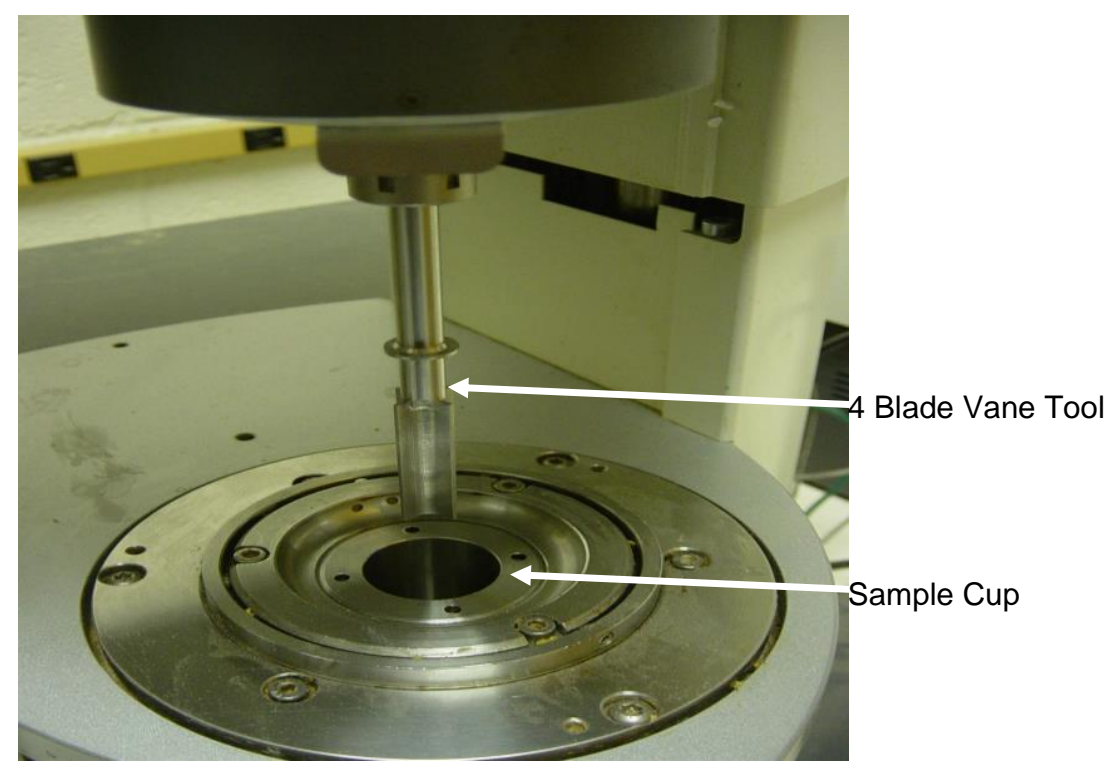

Figure 3 


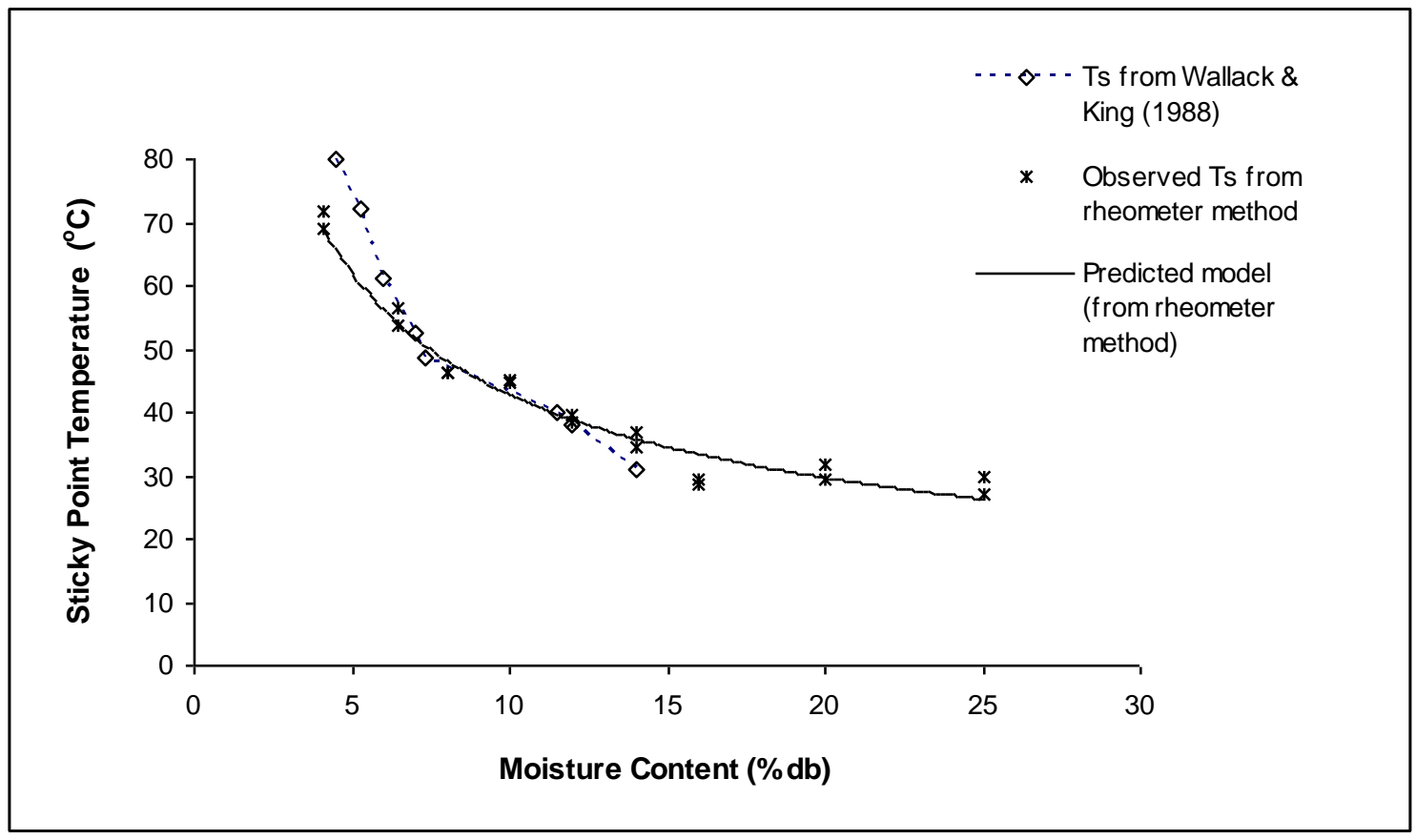

Figure 4 


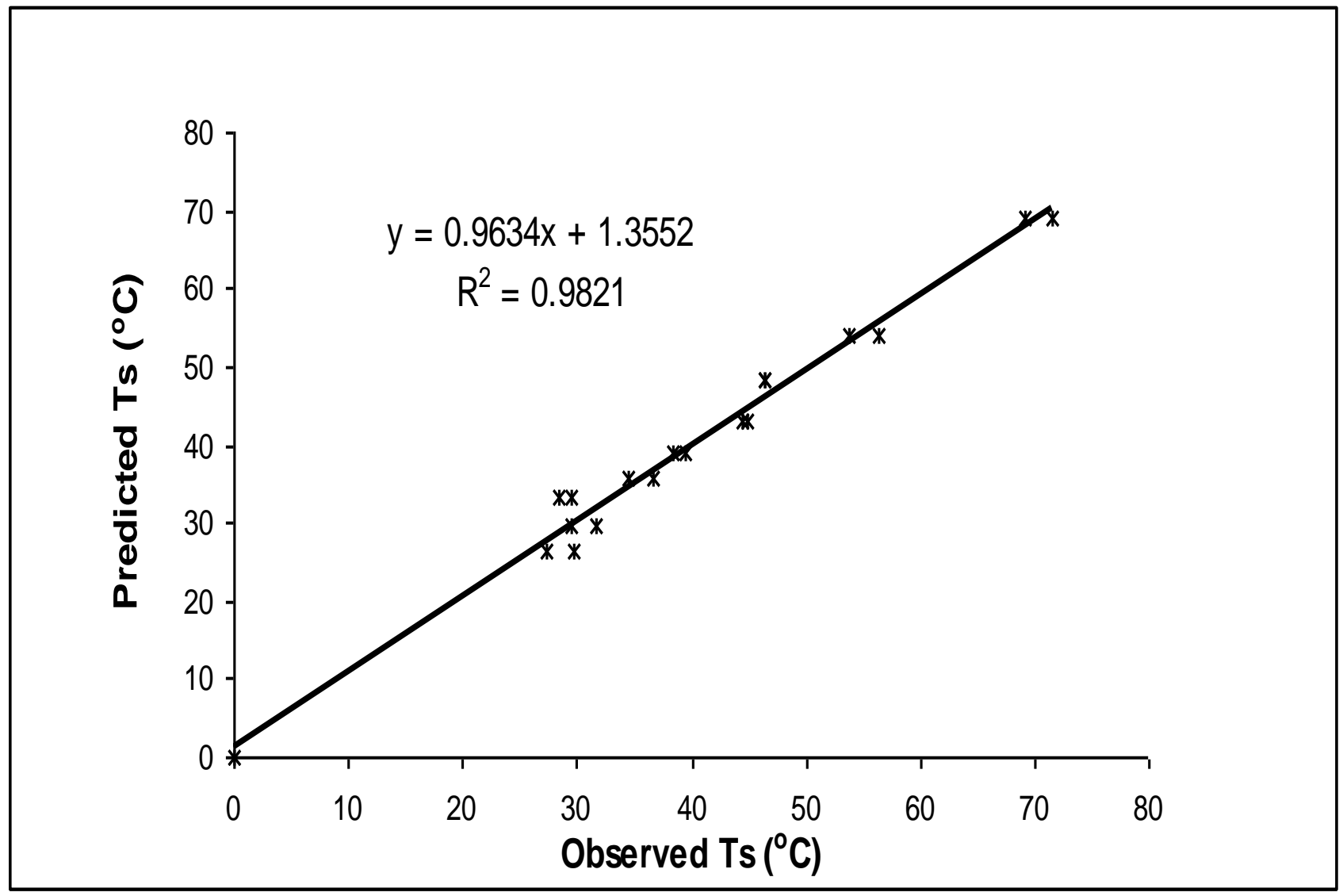

Figure 5 


\section{Figure Captions}

Figure 1: Typical sticky region and sticky point temperature (Ts) curves for food products, based on Kudra (2). For this study, non-sticky (discrete particles), lower boundary (Ts curve), and sticky region is considered for measurement purposes.

Figure 2: Experimental set up used in this study to measure the sticky point temperature (Ts) with a rheometer.

Figure 3: View of the 4 blade vane tool being inserted into the sample cup for Ts measurement. Figure 4: Comparison of Wallack and King (3) coffee powder data with Ts data obtained using the rheometer in this study. Predicted $\mathrm{Ts}=\mathrm{f}$ (moisture content) using a power law regression equation (model 1, Table I), $\mathrm{R}^{2}=0.97, \mathrm{SEM}=2.73$.

Figure 5: Relationship between observed Ts and predicted Ts for coffee powder. 